\title{
Identification and Characterization of Isolates of Phytophthora infestans Using Fatty Acid Methyl Ester (FAME) Profiles
}

\author{
Robert P. Larkin and Carol L. Groves, USDA, ARS, New England Plant, Soil, and Water Lab, Orono, ME 04469
}

\begin{abstract}
Larkin, R. P., and Groves, C. L. 2003. Identification and characterization of isolates of Phytophthora infestans using fatty acid methyl ester (FAME) profiles. Plant Dis. 87:1233-1243.

The utility of fatty acid profiles for characterization and differentiation of isolates of $P$. infestans was investigated. Two libraries of fatty acid methyl ester (FAME) profiles (one representing average genotype characteristics and one representing individual isolate characteristics) were established from at least eight replicate samples of each of 25 different isolates of $P$. infestans, including representative isolates of US-1, US-6, US-7, US-8, US-11, US-14, and US-17 genotypes. These libraries then were used to identify and characterize additional unknown isolates. Fatty acid profile characteristics also were compared with cultural and genetic characteristics of the isolates. FAME profiles for isolates of P. infestans were consistent over multiple extractions and distinctly different from profiles for isolates of other Phytophthora species, such as $P$. capsici and P. erythroseptica, as well as isolates of Pythium spp. and various other fungal groups. Overall, profiles from different isolates within the same genotype shared similar characteristics, although there was overlap among some genotypes. Incubation temperature, growth medium, and prolonged storage on agar media all significantly affected fatty acid profiles; however, when these conditions were kept constant, profiles were distinct, consistent, and reproducible over time. Isolate profiles were sufficiently specific that individual isolates could be distinctly identified by FAME profiles. In general, individual isolate characteristics were more determinant than genotype group characteristics, although genotype could be determined for most isolates tested. Results indicated that FAME profiles can be an additional tool useful for characterizing isolates and populations of $P$. infestans.
\end{abstract}

The recent resurgence of the late blight pathogen, Phytophthora infestans (Mont.) de Bary, as a major agricultural threat, as well as the associated changes in genetic complexity of this organism, have necessitated careful scrutiny and characterization of populations of $P$. infestans so that appropriate control methods can be implemented. Several techniques for molecular and genetic characterization of $P$. infestans, including allozyme analyses $(5,7)$, mitochondrial DNA haplotyping (10), and DNA genetic fingerprinting $(6,11)$, are available and routinely used to characterize different isolates of this organism. However, many isolates showing minor genetic differences or variant genotypes cannot be clearly distinguished with these tests. In addition,

Corresponding author: R. P. Larkin

E-mail: larkin@maine.edu

Mention of a trademark, proprietary product, or vendor does not constitute a guarantee or warranty of the product by the U.S. Department of Agriculture, and does not imply its approval to the exclusion of other products or vendors that may also be suitable.

Accepted for publication 21 May 2003.

Publication no. D-2003-0811-01R

This article is in the public domain and not copyrightable. It may be freely reprinted with customary crediting of the source. The American Phytopathological Society, 2003. much variability apparently exists in the epidemiological characteristics of different isolates which cannot be accounted for by the present genetic tests. Additional tools for further characterization would be useful, particularly ones that may account for potential epidemiological differences among isolates.

Analysis of cellular fatty acid composition routinely is used to characterize, differentiate, and identify genera, species, and strains of bacteria and yeasts $(1,2,18,20$, 28,29). Taxa are distinguishable by the types of fatty acids produced and the relative concentrations of individual fatty acids. In addition to genotype, fatty acid composition is strongly influenced by three primary environmental variables-growth substrate, incubation temperature, and incubation time-but results are highly reproducible, consistent, and conserved among different taxa when these factors are held constant $(18,27)$. Although fungi and related taxa generally produce fewer types and lower quantities of fatty acids than bacteria, there is growing evidence that fatty acid profiles also may be useful for the identification and characterization of fungi $(14,16,17,21,25)$. Fatty acid profiles have been used successfully to characterize and differentiate major groups and genera of fungi $(16,17,21)$, and species and subspecific groups of Penicillium (14), Rhizoctonia (22-25), and mycorrhizae $(9,15)$. Oomycetes, in the Kingdom Stra- menopila, which include the genera Phytophthora and Pythium, may have good potential for differentiation by fatty acids, because they produce several fatty acids not generally produced by true fungi (16). However, there is little information on fatty acid profiles for this group of organisms. Fatty acid profiling represents a relatively rapid, cost-effective, and efficient approach that may be useful for characterization of $P$. infestans, as well as other oomycete pathogens. It represents a different approach that may reveal aspects of variability among isolates of $P$. infestans not readily detected by other means. The objective of this study was to investigate the potential of using whole cell fatty acid methyl ester (FAME) profiles for the identification, characterization, and differentiation of isolates of $P$. infestans. Factors that might affect fatty acid production and therefore interfere with consistent characterization-such as growth media, incubation temperature, and length of time isolates are maintained on culture plateswere also examined.

\section{MATERIALS AND METHODS}

Isolates examined. Isolates of $P$. infestans were collected from diseased potato and tomato plants in Maine during the growing seasons of 1999 and 2000 (11). A core library of 25 isolates representing different genotypes and genetic characteristics was assembled from the isolates collected in 1999, known tester isolates, and isolates of different genotypes obtained from colleagues (Table 1). P. infestans was isolated by placing a small piece of blighted tissue in a sterile petri plate and covering the tissue with a thin slice of surface-disinfested $(0.5 \%$ sodium hypochlorite for $5 \mathrm{~min}$ ) potato tuber. The cultures were incubated at $18^{\circ} \mathrm{C}$ until $P$. infestans grew through the tuber slice and sporulated (3 to 5 days). Sporangia were removed by contact with a small block of agar on the tip of a sterile transfer needle and plated onto fresh Rye A (RA) agar (3) amended after autoclaving with $0.67 \mathrm{~g}$ of PCNB (97\% active ingredient), $0.1 \mathrm{~g}$ of benomyl, $0.02 \mathrm{~g}$ of rifampicin, $0.05 \mathrm{~g}$ of polymyxin $\mathrm{B}, 0.1 \mathrm{~g}$ of ampicillin, and 0.05 $\mathrm{g}$ of vancomycin per liter (RAA). Alternatively, isolations were made by surfacedisinfesting small pieces of blighted tissue, placing pieces onto RAA agar, and incubating and recovering as above. Singlezoospore colonies were produced for each isolate, and these were maintained on RA 
agar plates in the dark at $21^{\circ} \mathrm{C}$ and on RA slants under sterile mineral oil at $18^{\circ} \mathrm{C}$. Two isolates of Phytophthora capsici and six isolates of $P$. erythroseptica collected from diseased pepper plants and potato tubers, respectively, were obtained from Dave Lambert (University of Maine, Orono) as examples of other Phytophthora species for comparison with $P$. infestans. Five isolates of Pythium ultimum collected from soil in potato fields in Maine were also used to represent an additional oomycete genus for comparison. In addition, multiple isolates of several common soilborne fungi were also collected and used to demonstrate differences in FAME profiles among oomycetes and various fungal genera. These fungi included: Rhizoctonia solani (six isolates of anastomosis group AG3, four collected from diseased potato tubers in Maine and two obtained from Mark Cubeta, North Carolina State University); Fusarium oxysporum (eight isolates collected from soil); Verticillium spp. (two isolates collected from soil); Penicil- lium sp. (10 isolates of an as yet unidentified species associated with potato roots (13); and Trichoderma spp. (two isolates collected from soil). Isolates collected from soil or diseased plant tissue were plated on selective media, single-spored, and identified based on standard morphological and cultural characteristics. These isolates were cultured and maintained on potato dextrose agar (PDA) at $25^{\circ} \mathrm{C}$.

Mating type and mefenoxam sensitivity. Mating type of each isolate of $P$. infestans was determined by pairing with known A1 and A2 tester isolates on Rye B (RB) agar (3) and incubating cultures in the dark at $18^{\circ} \mathrm{C}$. Cultures were examined microscopically for oospore formation after 10 to 14 days. Isolates forming abundant oospores with the A1 isolates were rated as A2 mating type, and those that formed abundant oospores with the A2 isolates were rated as A1 mating type. Isolates also were tested for their sensitivity to the fungicide mefenoxam (Ridomil Gold EC, Novartis, Goldsboro, NC). Agar disks ( $5 \mathrm{~mm}$ diameter) of each isolate were placed in the center of a 100 -mm-diameter petri plate containing RB agar amended with mefenoxam at concentrations of 0,5 , and $100 \mu \mathrm{g} \mathrm{ml}^{-1}$. Three replicate plates of each concentration were used for each isolate, and the experiment was conducted three times. Cultures were incubated at $18^{\circ} \mathrm{C}$ in the dark, and colony diameter was measured at 7 and 10 days. Isolates were rated sensitive to the fungicide if growth at $5 \mu \mathrm{g} \mathrm{ml}^{-1}$ was less than $50 \%$ of the control $\left(0 \mu \mathrm{g} \mathrm{ml}^{-1}\right)$ and resistant if growth was greater than $50 \%$ of the control.

Allozyme analysis. Mycelia of each isolate of $P$. infestans were obtained by growth in pea broth (3) at $18^{\circ} \mathrm{C}$ for at least 2 weeks. Samples were prepared for allozyme analysis as described by Fraser et al. (5). Allozymes were determined at the glucose-6-phosphate isomerase (Gpi) locus by polyacrylamide gel electrophoresis (5) or by cellulose acetate electrophoresis (7). Gels were stained using a modification of the agar underlay stains of Goodwin et al.

Table 1. Cultural and genetic characteristics of isolates of Phytophthora infestans used in this study

\begin{tabular}{|c|c|c|c|c|c|c|c|c|}
\hline Isolate no. & $\begin{array}{c}\text { Mating } \\
\text { type }\end{array}$ & $G p i^{\mathrm{u}}$ & $\begin{array}{c}\text { US- } \\
\text { genotype }^{u}\end{array}$ & Mefenoxam $^{v}$ & mtDNA $^{w}$ & RG57 fingerprint $^{x}$ & Isolate source & Host \\
\hline $99-1$ & A1 & $86 / 100$ & 1 & $\mathrm{~S}$ & $\mathrm{Ib}$ & 1010101011001101000110011 & Nebraska ${ }^{y}$ & Potato \\
\hline $99-24$ & A1 & $86 / 100$ & 1 & $\mathrm{~S}$ & $\mathrm{Ib}$ & 1010101001001101000110011 & Unknown & Potato \\
\hline $99-33$ & A1 & $86 / 100$ & 1 & $\mathrm{~S}$ & $\mathrm{Ib}$ & 1010101011001101000110011 & $\mathrm{NC}^{\mathrm{z}}$ & Potato \\
\hline $99-25$ & A1 & $100 / 100$ & 6 & $\mathrm{R}$ & $\mathrm{IIb}$ & 1010111001001100010110011 & Unknown & Potato \\
\hline $99-2$ & $\mathrm{~A} 2$ & $100 / 111$ & 7 & $\mathrm{R}$ & Ia & 1000100001001101010110011 & Texas $^{\mathrm{y}}$ & Potato \\
\hline $99-30$ & $\mathrm{~A} 2$ & $100 / 111$ & 7 & $\mathrm{R}$ & Ia & 1000100001001101000110111 & $\mathrm{NC}^{\mathrm{z}}$ & Potato \\
\hline $99-3$ & $\mathrm{~A} 2$ & $100 / 111 / 122$ & 8 & $\mathrm{R}$ & Ia & 1000100001001101000110111 & New York ${ }^{\mathrm{y}}$ & Potato \\
\hline $99-23$ & $\mathrm{~A} 2$ & $100 / 111 / 122$ & 8 & $\mathrm{R}$ & Ia & 1000100001001101000110111 & Unknown & Potato \\
\hline $99-26$ & $\mathrm{~A} 2$ & $100 / 111 / 122$ & 8 & $\mathrm{R}$ & Ia & 1000100001001101000110111 & Limestone, ME & Potato \\
\hline $99-27$ & $\mathrm{~A} 2$ & $100 / 111 / 122$ & 8 & $\mathrm{R}$ & Ia & 1000100001001101000110111 & Limestone, $\mathrm{ME}$ & Potato \\
\hline $99-28$ & $\mathrm{~A} 2$ & $100 / 111 / 122$ & 8 & $\mathrm{R}$ & Ia & 1000100001001101000110111 & Limestone, ME & Potato \\
\hline $99-29$ & $\mathrm{~A} 2$ & $100 / 111 / 122$ & 8 & $\mathrm{R}$ & Ia & 1000100001001101000110111 & $\mathrm{NC}^{\mathrm{z}}$ & Potato \\
\hline $99-35$ & $\mathrm{~A} 2$ & $100 / 111 / 122$ & 8 & $\mathrm{R}$ & Ia & 1000100001001101000110111 & Presque Isle, ME & Potato \\
\hline $99-40$ & $\mathrm{~A} 2$ & $100 / 111 / 122$ & 8 & $\mathrm{R}$ & Ia & 1000100001001101000110111 & Easton, $\mathrm{ME}$ & Potato \\
\hline $99-46$ & $\mathrm{~A} 2$ & $100 / 111 / 122$ & 8 & $\mathrm{~S}$ & Ia & 1000100001001101000110111 & Bridgewater, ME & Potato \\
\hline $99-65$ & $\mathrm{~A} 2$ & $100 / 111 / 122$ & 8 & $\mathrm{R}$ & Ia & 1000100001001101000110111 & Presque Isle, ME & Potato \\
\hline $99-72 \mathrm{~A}$ & A1 & $100 / 111 / 122$ & 8 & $\mathrm{~S}$ & Ia & 1000100001001101000110011 & Aroostook Farm & Potato \\
\hline $99-4$ & A1 & $100 / 100 / 111$ & 11 & $\mathrm{R}$ & $\mathrm{IIb}$ & 1010111001001101010110011 & Washington ${ }^{y}$ & Potato \\
\hline $99-22$ & A1 & $100 / 100 / 111$ & 11 & $\mathrm{R}$ & $\mathrm{IIb}$ & 1010111001001101010110011 & Unknown & Potato \\
\hline $99-13 B$ & A1 & $100 / 122$ & 14 & $\mathrm{R}$ & $\mathrm{Ia}$ & 1000100001001101000110111 & Maine & Potato \\
\hline $99-17$ & $\mathrm{~A} 2$ & $100 / 122$ & 14 & $\mathrm{~S}$ & $\mathrm{Ia}$ & 1000100001001101000110111 & Limestone, ME & Potato \\
\hline $99-64$ & A1A2 & $100 / 122$ & 14 & $\mathrm{~S}$ & Ia & 1000100001001101000110111 & Aroostook Farm & Potato \\
\hline $99-72 B$ & $\mathrm{~A} 2$ & $100 / 122$ & 14 & $\mathrm{~S}$ & Ia & 1000100001001101000110111 & Aroostook Farm & Potato \\
\hline 99-97 & $\mathrm{A} 2$ & $100 / 122$ & 14 & $\mathrm{R}$ & Ia & 1000100001001101000110111 & New York ${ }^{\mathrm{y}}$ & Potato \\
\hline $99-5$ & A1 & $100 / 122$ & 17 & $\mathrm{R}$ & Ia & 1010001001001101010110011 & Florida ${ }^{\mathrm{y}}$ & Tomato \\
\hline $00-15$ & A1 & $100 / 100$ & - & ND & Ia & 1010001001001101000110011 & Farmington, $\mathrm{ME}$ & Tomato \\
\hline $00-22$ & A1 & $100 / 100$ & - & $\mathrm{S}$ & Ia & 1010001001001101000110011 & New Sharon, ME & Tomato \\
\hline $00-87$ & A1 & $100 / 100$ & - & ND & Ia & ND & New Vineyard, ME & Tomato \\
\hline $00-3$ & $\mathrm{~A} 2$ & $100 / 111$ & - & $\mathrm{R}$ & Ia & 1000100001001101000110111 & Van Buren, ME & Potato \\
\hline $00-6$ & A2 & $122 / 122$ & - & $\mathrm{R}$ & Ia & 1000100001001101000110111 & Van Buren, ME & Potato \\
\hline $00-73$ & A2 & $122 / 122$ & - & $\mathrm{S}$ & $\mathrm{Ia}$ & 1000100001001101000110111 & Presque Isle, ME & Potato \\
\hline $00-1$ & A2 & $100 / 111 / 122$ & 8 & ND & Ia & ND & Van Buren, ME & Potato \\
\hline $00-38$ & $\mathrm{~A} 2$ & $100 / 111 / 122$ & 8 & ND & Ia & ND & Caribou, ME & Potato \\
\hline $00-39$ & $\mathrm{~A} 2$ & $100 / 122$ & 14 & $\mathrm{R}$ & Ia & 1000100001001101000110111 & Caribou, ME & Potato \\
\hline $00-58$ & $\mathrm{~A} 2$ & $100 / 122$ & 14 & $\mathrm{~S}$ & Ia & 1000100001001101000110111 & Presque Isle, ME & Potato \\
\hline
\end{tabular}

" Glucose-6-phosphate isomerase assay; US genotype designations based on Gpi assay. Hyphen represents variant genotype that has no US designation $(7,8)$.

${ }^{v}$ Sensitivity to mefenoxam: $\mathrm{S}=$ sensitive, growth less than $50 \%$ of control $\left(0 \mu \mathrm{g} \mathrm{ml} \mathrm{m}^{-1}\right)$ at $5 \mu \mathrm{g} \mathrm{m} \mathrm{l}^{-1} ; \mathrm{R}=\mathrm{resistant}$, growth greater than $50 \%$ of control at 5 $\mu \mathrm{g} \mathrm{ml} \mathrm{m}^{-1} ; \mathrm{ND}=$ not determined.

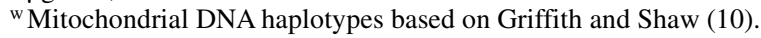

x Presence (1) or absence (0) of RG57 fingerprint bands 1 to 25 (Goodwin et al. [6]) are indicated from left to right. DNA fingerprint band 4 is not reproducible and was not detected in this study. ND = not determined.

y Tester isolate obtained from W. E. Fry, Cornell University.

${ }^{\mathrm{z}}$ Isolate obtained from M. Cubeta, North Carolina State University. 
(7). The modification was that the agar was omitted and the stain was poured directly over the gels. Known isolates of the clonal genotypes US-1, US-6, US-8, US-11, and US-14 were used as standards. Migration distances of proteins from the unknown and known isolates were compared. Alleles in individual isolates were scored based on the migration of their proteins relative to the protein produced at the 100 allele, which is the most commonly occurring enzyme species (7).

Genetic characterization. Isolates of $P$. infestans were characterized by mitochondrial DNA haplotyping (10) and restriction fragment length polymorphism (RFLP) genetic fingerprint analysis using the RG57 species-specific probe for $P$. infestans (6). Pea broth cultures of $P$. infestans were grown at $18^{\circ} \mathrm{C}$ for at least 2 weeks, and mycelia were harvested by vacuum filtration and frozen at $-20^{\circ} \mathrm{C}$. DNA was extracted from mycelia by the cetyltrimethylammonium bromide (CTAB) procedure (27) and then resuspended in TE $(10 \mathrm{mM}$ Tris-HCl, $0.1 \mathrm{mM}$ EDTA, pH 8.0). Haplotypes of mitochondrial DNA were determined using the polymerase chain reaction (PCR), primer sets P2 and P4 (10), and procedures described previously (11). For RFLP analysis, DNA was extracted from frozen mycelia using procedures originally developed by Goodwin et al. (6) and as modified by Groves (11). An extracted, purified, washed, and dried DNA sample was air-dried prior to resuspension in 500 $\mu \mathrm{l}$ of TE. DNA was quantified by electrophoresis on agarose gels with a dilution series of known $\lambda$ DNA. DNA of $P$. infestans (1 to $2 \mu \mathrm{g}$ ) was digested with EcoR1, electrophoresed on $0.8 \%$ agarose gels, and then transferred to a nylon membrane (Hybond-N+, Amersham Pharmacia Biotechnology, Inc.). RFLP analysis was performed using the Random Primer Fluorescein Labeling Kit with AntifluoresceinAP (Perkin Elmer Life Sciences Inc., Boston, MA) according to the manufacturer's directions with a modification in probe purification. The fluorescein labeled RG57 (6) probe was purified by precipitation in absolute ethanol.

Effects of growth media, incubation temperature, and prolonged plate culture. Culture conditions for growth of fungal (non-oomycete) isolates for fatty acid analysis followed the protocols established and recommended by MIDI, Inc. (Newark, DE), which included growing each sample in $40 \mathrm{ml}$ of Sabaraud broth (SB) on a rotary shaker $(120 \mathrm{rpm})$ at $28^{\circ} \mathrm{C}$ for 2 to 4 days. However, $P$. infestans grows much more slowly than most fungi, requiring about 14 or more days to cover more than one-half of a petri plate, does not grow at all on SB, potato dextrose broth, or PDA, and grows best at temperatures of 18 to $25^{\circ} \mathrm{C}$ (12). Therefore, various growth media suitable for oomycetes were evaluated for fatty acid production. Se- lected tester isolates representative of the genotypes US-1, US-8, US-11, and US-14 were grown in 40-ml pea broth (PB), on pea broth agar (PA) plates, and on RA agar plates at $25^{\circ} \mathrm{C}$ for 14 days. Fatty acid profiles of these isolates were compared among media types for variability, consistency, and reproducibility. In all subsequent trials, oomycete cultures were grown on PA plates at $25^{\circ} \mathrm{C}$ for fatty acid analyses.

PB cultures of the oomycetes and SB cultures of the other fungi were harvested on a cellulose filter by vacuum filtration and transferred to clean culture tubes $(13 \times$ $100 \mathrm{~mm}$ ) with Teflon-coated screw caps for fatty acid extraction. Agar cultures were harvested through a modification of the procedure of Stevens Johnk and Jones (22), in which a doughnut-shaped plug (inner diameter $3 \mathrm{~cm}$ and outer diameter 7 $\mathrm{cm}$ ) of actively growing mycelium was cut from each plate, placed in $60 \mathrm{ml}$ of deionized water, and microwaved to boiling (about $1 \mathrm{~min}$ ). The mycelial mat was removed and dried briefly on a paper towel. Mats were placed in Teflon-lined screwcap culture tubes $(13 \times 100 \mathrm{~mm})$ for fatty acid extraction (18). All harvested mycelial mats were stored at $-20^{\circ} \mathrm{C}$ until fatty acids were extracted. Each agar plate or broth flask represented one sample for extraction. For some particularly slow-growing isolates, multiple plates were necessary to produce enough mycelium for a single sample. In general, three replicate samples of each isolate were used for each fatty acid analysis, and multiple analyses (three to eight) were conducted for each isolate over time.

Effect of incubation temperature on fatty acid production among isolates of $P$. infestans was examined using selected tester isolates (99-1, 99-2, 99-3, 99-4, and 99-97) representative of different genotypes. Isolates were grown on PA at both 21 and $25^{\circ} \mathrm{C}$, fatty acids extracted, and fatty acid profiles compared among isolates and incubation temperature. A minimum of six extractions for each isolate/temperature combination was used, and the experiment was repeated.

Cultures of selected tester isolates (99-1, 99-2, 99-3, 99-4, and 99-97) also were maintained on agar plates for extended periods to examine the effect of repeated transfer and prolonged culture storage on fatty acid production. Cultures were grown on RA at $21^{\circ} \mathrm{C}$ in the dark and transferred to new plates approximately every 2 months for 1 year. Fresh PA plates were made from these cultures at 1, 2, 4, 6, 9, and 12 months, incubated as described above, and analyzed for fatty acids. A minimum of six extraction samples were used for each isolate/time combination.

Extraction and analysis of fatty acids. Whole cell FAME extractions were accomplished according to the standard protocols developed for the Microbial Identi- fication System (MIS; MIDI, Inc., 1998). Briefly, lipids were saponified by adding 1 $\mathrm{ml}$ of $3.25 \mathrm{M} \mathrm{NaOH}$ in methanol to each sample tube; the mixture was mixed, heated in a $100^{\circ} \mathrm{C}$ water bath for $5 \mathrm{~min}$, mixed again, heated for an additional 25 min, and cooled in cold water. Samples then were methylated by adding $2 \mathrm{ml}$ of $3.25 \mathrm{~N} \mathrm{HCl}$ in methanol, mixing, placing in an $80^{\circ} \mathrm{C}$ water bath for $10 \mathrm{~min}$, and then cooling in cold water. FAMEs were extracted from this solution by adding $1.3 \mathrm{ml}$ of a 1:1 methyl tert-butyl ether:hexane mixture and placing on a rotary mixer for $10 \mathrm{~min}$. The top organic phase was transferred by pipette to a clean $13 \times 100 \mathrm{~mm}$ culture tube and washed using $3 \mathrm{ml}$ of dilute $\mathrm{NaOH}$. The organic phase then was transferred to a glass GC vial for subsequent analysis by gas chromatography by an automated procedure developed by MIDI using an HP 6890 gas chromatograph (Hewlett-Packard, Wilmington, DE) with an HP Ultra-2 capillary column and flame ionization detector. The fatty acids were identified according to the Fungi method and peak naming table software developed for the MIS. The fatty acid nomenclature used is: total number of carbon atoms: number of double bonds followed by the position of the double bond from the methyl end $(\omega)$ of the molecule. Cis and trans geometry are indicated by the suffixes $\mathrm{c}$ and t, respectively. Anteiso- and iso-branching are indicated by the suffixes ant and iso, respectively.

Library generation and evaluation. Profile libraries were constructed from a minimum of eight to as many as 16 separate sample extractions for each isolate, which were conducted over time. Two library databases were established for $P$. infestans: one consisting of profiles of individual isolates (isolate library) and one consisting of profile entries grouped by genotype based on Gpi analysis and USgenotype designations (genotype library). An additional library was established consisting of profile entries for each of the other fungi evaluated (fungal library). Fatty acid profiles were compared using Library Generation Software (MIDI, Inc.), which determined relatedness by comparing the profile of a given sample with each library entry. A similarity index (a value between 0 and 1) indicated how closely each sample profile matched that of a library entry. Dendrograms of the library entries also were constructed using an unweighted pair-group comparison, and Euclidian distance (i.e., the distance in two-dimensional space between two entries) was used to depict relatedness among entries. In addition, all profile data were subjected to principal components analysis (PCA) using the covariance matrix, with principal components 1 through 4 analyzed by multivariate analysis of variance (ANOVA) and significance determined by Wilk's Lambda $F$ test. Relative percent- 
ages of individual fatty acids and other univariate factors were analyzed by standard ANOVA, and means were separated by Fisher's protected LSD test.

Capability of the genotype and isolate libraries to positively identify an unknown isolate was evaluated in a blind test, in which five previously profiled isolates were chosen and assigned an arbitrary letter designation (A through $\mathrm{E}$ ) by a third party. A minimum of six separate samples were analyzed for each isolate, and the average profile was compared with the profiles in the genotype and isolate libraries and tentatively identified. A similarity index of 0.6 or higher was considered a positive identification (as long as no other entry was within 0.05 ), and an index of 0.5 to 0.6 was considered a tentative identification. The genotype library also was used in the same way to characterize 10 additional new isolates collected in Maine in 2000, including some with novel variant genotypes (Table 1) (11).

\section{RESULTS}

Cultural and genetic characteristics. The 25 isolates of $P$. infestans used to establish the profile libraries contained isolates with various different genetic characteristics, including seven of the designated US-genotypes (based on Gpi analysis), mitochondrial haplotypes Ia, Ib, and IIb, mefenoxam sensitivity and resistance, and eight different RG57 fingerprint patterns (Table 1). The genetic characteristics of the tester isolates were as expected for their respective genotypes. Most of the Maine isolates showed typical characteristics of US- 8 and US-14 genotypes, with a few minor variants (Table 1). Isolate 99-72A (Gpi 100/111/122) was mating type A1 instead of the typical A2 characteristic of US- 8 genotypes. This isolate also had an RG57 fingerprint slightly different from the typical US- 8 fingerprint, missing band 23. Isolate 99-64 was designated an A1A2 mating type because it produced abundant oospores with both A1 and A2 tester isolates in repeated crosses on Rye B agar. This interaction was checked and verified as definitive crosses with both mating types.

FAME profiles. All isolates of $P$. infestans produced eight primary fatty acids, which accounted for 97 to $99 \%$ of total fatty acid content (Table 2). These eight predominant fatty acids consisted of two saturated straight-chain (14:0 and 16:0), two monounsaturated $(16: 1 \omega 7 \mathrm{c}$ and $18: 1$ $\omega 9 \mathrm{c})$, and four long-chain polyunsaturated (18:2 $\omega 6 \mathrm{c}, 18: 3 \omega 6 \mathrm{c}, 20: 4 \omega 6 \mathrm{c}$, and 20:5 $\omega 3 \mathrm{c})$ fatty acids. Four additional fatty acids $(18: 0,18: 03 \mathrm{OH}, 16: 1 \omega 9 \mathrm{c}$, and 20:1 $\omega 9 \mathrm{c})$ were observed in a majority of isolates, but as minor components $(<1 \%$ of total content). Several other fatty acids (10:0, 12:0, $14: 1 \omega 5 \mathrm{c}, 15: 0$ iso $2 \mathrm{OH}, 18: 1 \omega 7 \mathrm{c}$, and 20:0 iso) were occasionally, but not consistently, observed in trace quantities (always $<0.5 \%$ of total content) in some isolates. FAME profiles of each isolate were generally consistent among replicate samples and multiple extractions conducted over time. The other oomycetes examined $(P$. capsici, $P$. erythroseptica, and Pythium ultimum) also contained these same predominant fatty acids, but the relative percentages were different among the taxa (Table 2). Isolates of Pythium ultimum also contained several minor component $(<1 \%$

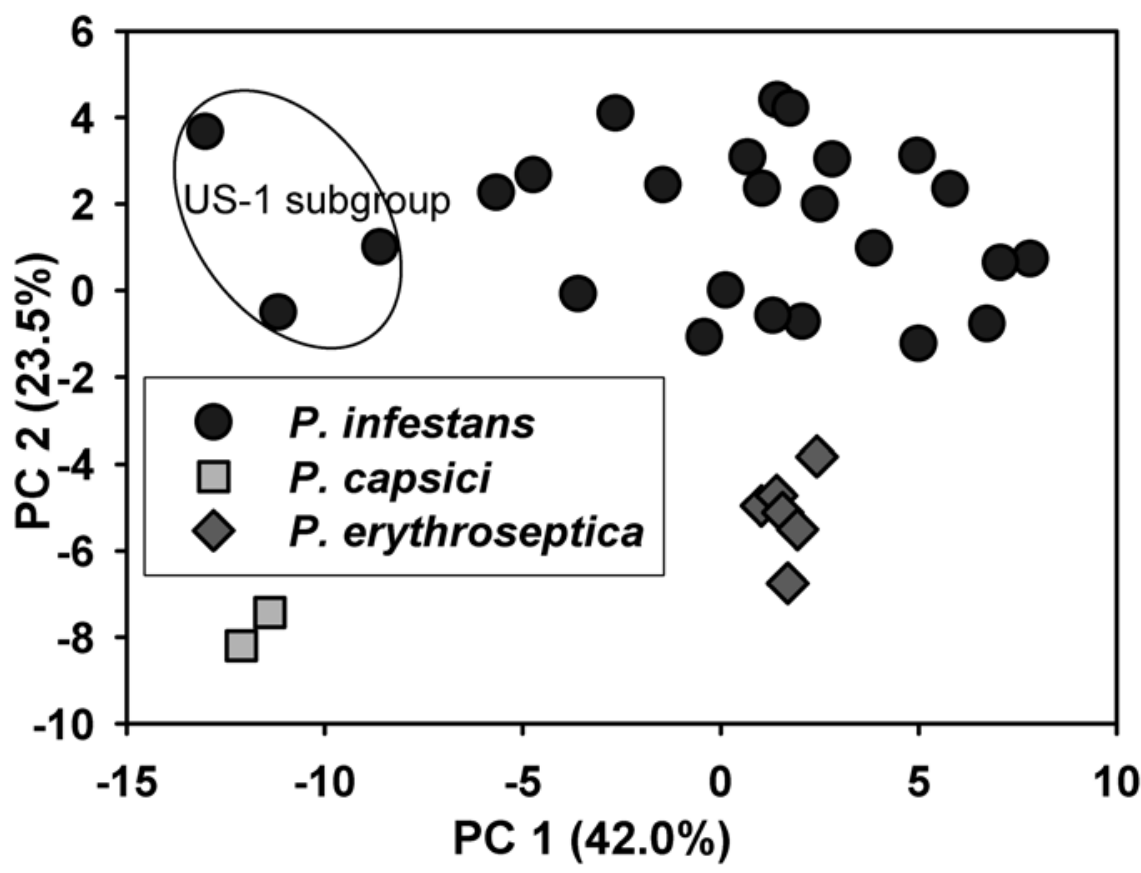

Fig. 1. Relationship of fatty acid profiles among isolates of Phytophthora infestans, P. capsici, and $P$. erythroseptica as represented by an ordination plot of PC 1 and PC 2 from principal components (PC) analysis. Values in parentheses represent percentage of total variability accounted for by each PC.

Table 2. Relative cellular fatty acid composition (\% of total) for subspecific genotype groups within Phytophthora infestans and isolates of $P$. capsici, $P$. erythroseptica, and Pythium ultimum

\begin{tabular}{|c|c|c|c|c|c|c|c|c|c|c|c|}
\hline \multirow[b]{2}{*}{ Fatty acid } & \multicolumn{7}{|c|}{ P. infestans genotype ${ }^{\mathrm{x}}$} & \multirow[b]{2}{*}{$\begin{array}{l}\text { P. capsici } \\
\text { (2) }\end{array}$} & \multirow[b]{2}{*}{$\begin{array}{c}\text { P. eryth. } \\
\text { (6) }\end{array}$} & \multirow[b]{2}{*}{$\begin{array}{c}\text { Pythium } \\
\text { ultimum (5) }\end{array}$} & \multirow[b]{2}{*}{$\mathbf{L S D}^{\mathbf{z}}$} \\
\hline & $\begin{array}{c}\text { US-1 } \\
(3)^{\mathrm{y}}\end{array}$ & $\begin{array}{c}\text { US-6 } \\
(1)\end{array}$ & $\begin{array}{l}\text { US-11 } \\
\text { (2) }\end{array}$ & $\begin{array}{l}\text { US-17 } \\
\text { (1) }\end{array}$ & $\begin{array}{l}\text { US-7 } \\
(2)\end{array}$ & $\begin{array}{c}\text { US-8 } \\
(11)\end{array}$ & $\begin{array}{c}\text { US-14 } \\
(5)\end{array}$ & & & & \\
\hline $14: 0$ & 12.5 & 22.6 & 24.4 & 17.4 & 21.2 & 25.0 & 24.9 & 12.3 & 22.4 & 6.7 & 2.1 \\
\hline $16: 1 \omega 7 \mathrm{c}$ & 1.8 & 3.3 & 4.5 & 3.8 & 3.0 & 2.6 & 2.8 & 3.5 & 5.3 & 7.9 & 0.6 \\
\hline $16: 0$ & 21.4 & 20.1 & 20.2 & 24.3 & 19.4 & 17.6 & 16.9 & 27.3 & 19.4 & 19.1 & 1.2 \\
\hline $18: 3 \omega 6 c$ & 2.3 & 1.2 & 1.2 & 1.8 & 1.1 & 1.7 & 1.6 & 1.5 & 1.9 & 2.1 & 0.3 \\
\hline $18: 2 \omega 6 \mathrm{c}$ & 25.7 & 28.4 & 25.2 & 26.8 & 26.7 & 23.6 & 20.2 & 18.9 & 20.5 & 18.8 & 1.4 \\
\hline $18: 1 \omega 9 \mathrm{c}$ & 10.4 & 4.8 & 8.1 & 4.7 & 6.4 & 9.9 & 9.3 & 12.7 & 8.8 & 15.6 & 1.5 \\
\hline $20: 4 \omega 6 c$ & 2.8 & 1.8 & 0.8 & 2.4 & 2.4 & 2.0 & 3.5 & 5.1 & 7.3 & 7.9 & 0.6 \\
\hline $20: 5 \omega 3 c$ & 20.4 & 15.9 & 12.4 & 17.6 & 18.7 & 16.3 & 18.8 & 14.4 & 11.6 & 10.6 & 2.0 \\
\hline 18:0 & 1.0 & 0.2 & 0.2 & 0.0 & 0.1 & 0.3 & 0.4 & 1.2 & 0.2 & 1.4 & 0.3 \\
\hline 18:0 3OH & 0.7 & 0.1 & 0.9 & 0.3 & 0.6 & 0.2 & 0.5 & 1.4 & 0.6 & 0.7 & 0.3 \\
\hline $16: 1 \omega 9 c$ & 0.0 & 0.9 & 0.2 & 0.0 & 0.1 & 0.0 & 0.1 & 0.0 & 0.1 & 0.6 & 0.1 \\
\hline $20: 1 \omega 9 \mathrm{c}$ & 0.8 & 0.1 & 0.3 & 0.1 & 0.2 & 0.3 & 0.3 & 0.6 & 0.0 & 1.9 & 0.3 \\
\hline Total & 99.8 & 99.4 & 98.4 & 99.2 & 99.9 & 99.5 & 99.3 & 98.9 & 98.1 & 93.3 & \\
\hline
\end{tabular}

${ }^{\mathrm{x}}$ US genotype designations represent known differences in genetic characteristics based on Gpi allozyme assay $(7,8)$ as described in Table 1.

${ }^{y}$ Number of isolates tested. At least eight replicate samples of each isolate were grown on pea broth agar for 14 days (P. infestans) or 7 days (other species) at $25^{\circ} \mathrm{C}$, and fatty acid data were averaged over all isolates within each group.

${ }^{\mathrm{z}} \mathrm{LSD}=$ value for Fisher's protected least significant difference test. Means within rows that differ by more than this value are significantly different at $P=0.05$. 
content) fatty acids (17:1 $\omega 8 \mathrm{c}, 20: 0,20: 2$ $\omega 6 c, 20: 1 \omega 6 c)$ that were not observed in any of the Phytophthora isolates. Principal component analysis of these FAME profiles demonstrated distinct differences among the Phytophthora species, as well as considerable variability among isolates of P. infestans (Fig. 1). Isolates of the US-1 genotype, in particular, had profiles different from all other isolates of $P$. infestans and formed a separate subgroup. Profile differences between $P$. capsici and P. erythroseptica were based primarily on 14:0 and 16:0 content (primary components of PC 1), whereas differences between these species and $P$. infestans were determined mainly by $20: 5 \omega 3 \mathrm{c}, 18: 1 \omega 9 \mathrm{c}$, and $18: 2$ $\omega 6 c$ content (main components of PC 2) (Fig. 1, Table 2).

FAME profiles of all of the oomycetes were drastically different from those of the representative fungal genera examined (Rhizoctonia, Penicillium, Trichoderma, Verticillium, and Fusarium spp.), which were dominated by three predominant fatty acids (18:2 $\omega 6 \mathrm{c}, 18: 1 \omega 9 \mathrm{c}$, and 16:0) and four to five minor constituents (Table 3 ). None of the fungal genera contained 18:3 $\omega 6 c$ or the 20-carbon fatty acids (20:4 $\omega 6 c$, $20: 5 \omega 3 c$, and $20: 1 \omega 9 \mathrm{c}$ ) found in the oomycetes, but some fungi also contained fatty acids not observed in the oomycete isolates $(15: 0,17: 0,17: 1 \omega 8 \mathrm{c}, 20: 1 \omega 11 \mathrm{c})$. In addition, the relative percentages of the fatty acids that were common among oomycetes and fungi were quite different, resulting in profiles readily distinguishable among taxa. These differences are illustrated in a dendrogram depicting the relatedness of FAME profiles among these taxa (Fig. 2).

Isolates of $P$. infestans within genotype groups based on Gpi analysis also tended to have similar profile characteristics, resulting in some significant differences among genotypes (Table 2). Isolates of US1 contained significantly lower percentages of $14: 0$ and $16: 1 \omega 7 \mathrm{c}$ and higher percentages of 18:3 $\omega 6 \mathrm{c}$ than all other isolates. This genotype also contained percentages of 20:5 $\omega 3 \mathrm{c}$ and 18:1 $\omega 9 \mathrm{c}$ that were higher than isolates in most other genotypes. The two genotypes with the largest number of isolates represented, the closely related US- 8 and US-14, were similar and had relatively high amounts of 14:0 and low amounts of 16:0, 16:1 $\omega 7 \mathrm{c}$, and 18:2 $\omega 6 \mathrm{c}$. There were some differences, however, as isolates of US-14 also contained the lowest amount of 18:2 $\omega 6 \mathrm{c}$ and highest amount of 20:4 $\omega 6$ c compared with all other genotypes (Table 2).

Overall differences in FAME profiles among genotypes could be distinguished by PCA and multivariate ANOVA. However, there was considerable variability among isolates within a given genotype and overlap among these genotype groups. Ordination plots of principle components (PC) 1 and 2 of individual isolates within each genotype (Fig. 3A) and average values for each genotype (Fig. 3B) illustrate overall genotype characteristics and the variability among isolates within genotypes. PC 1 and 2 accounted for 46.4 and $23.2 \%$ of the variability among isolates, but were not sufficient to clearly distinguish all genotype groups. Further differentiation among genotypes was achieved using PC 1 to 3, which accounted for $90.5 \%$ of the total variability among isolates and indicated significant differences among all genotype groups (Fig. 4). The fatty acids most responsible for differentiation along PC 1 were 14:0 and 20:5 $\omega 3 \mathrm{c}$. PC 2 was determined primarily by $20: 5$ $\omega 3 \mathrm{c}, 18: 2 \omega 6 \mathrm{c}$, and 16:0; 18:1 $\omega 9 \mathrm{c}$ was most important in determining PC 3 . The overall relatedness of FAME profiles among the different genotypes within $P$. infestans and the other species of Phytophthora is illustrated in a dendrogram (Fig. 5). The US-1 genotype was distinct from all other genotypes and had a FAME profile more similar to, but still quite distinct from, that of $P$. capsici than that of other isolates of $P$. infestans. This similarity to profiles of $P$. capsici was based primarily on content of 14:0, but contents of other primary fatty acids (i.e., 16:0, 18:2 $\omega 6 \mathrm{c}$, and $20: 5 \omega 3 \mathrm{c}$ ) were very different from $P$. capsici and more similar to other isolates of $P$. infestans (Table 2). When grouped by mating type, profiles from A1 isolates were also distinct from those of A2 (data not shown).

Effect of incubation temperature, growth medium, and prolonged plate culture. Incubation temperature (21 or $25^{\circ} \mathrm{C}$ ) significantly affected fatty acid production among the isolates tested, but the effects of temperature were minor compared with those associated with genotype. In addition, different isolates responded differently to temperature (Table 4). Overall, increasing incubation temperature from 21 to $25^{\circ} \mathrm{C}$ resulted in increased amounts of 16:0, 18:2 $\omega 6 \mathrm{c}$, and $18: 1 \omega 9 \mathrm{c}$, and de-

Table 3. Relative cellular fatty acid composition (\% of total) for isolates of selected fungal species

\begin{tabular}{lccccc}
\hline Fatty acid & $\begin{array}{c}\text { Rhizoctonia } \\
\text { solani }(\mathbf{6})^{\mathbf{z}}\end{array}$ & $\begin{array}{c}\text { Trichoderma } \\
\text { spp. (2) }\end{array}$ & $\begin{array}{c}\text { Penicillium } \\
\text { sp. (10) }\end{array}$ & $\begin{array}{c}\text { Verticillium } \\
\text { sp. (2) }\end{array}$ & $\begin{array}{c}\text { Fusarium } \\
\text { oxysporum (8) }\end{array}$ \\
\hline $14: 0$ & 0.0 & 0.5 & 0.2 & 0.1 & 0.7 \\
$15: 0$ & 0.9 & 0.1 & 0.2 & 0.0 & 0.0 \\
$16: 1 \omega 7 \mathrm{c}$ & 0.5 & 1.2 & 0.4 & 0.9 & 1.2 \\
$16: 0$ & 7.5 & 22.3 & 15.4 & 15.3 & 19.0 \\
$17: 1 \omega 8 \mathrm{c}$ & 1.5 & 0.0 & 1.4 & 0.0 & 0.0 \\
$17: 0$ & 0.6 & 0.0 & 1.1 & 0.0 & 0.0 \\
$18: 2 \omega 6 \mathrm{c}$ & 66.8 & 50.1 & 54.1 & 37.0 & 40.3 \\
$18: 1 \omega 9 \mathrm{c}$ & 20.5 & 23.4 & 23.6 & 44.8 & 32.2 \\
$18: 0$ & 1.3 & 1.7 & 2.7 & 1.3 & 5.4 \\
$20: 1 \omega 11 \mathrm{c}$ & 0.0 & 0.4 & 0.0 & 0.2 & 0.0 \\
Total & 99.6 & 99.7 & 99.1 & 99.6 & 98.8 \\
\hline
\end{tabular}

${ }^{\mathrm{z}}$ Number of isolates tested. At least eight replicate samples of each isolate were grown in Sabaraud broth for 2 to 4 days at $28^{\circ} \mathrm{C}$, and fatty acid data were averaged over all isolates for each fungus.

Rhizoctonia solani -AG3 (6)

Trichoderma spp. (2)

Penicillium sp. (10)

Fusarium oxysporum (8)

Verticillium spp. (2)
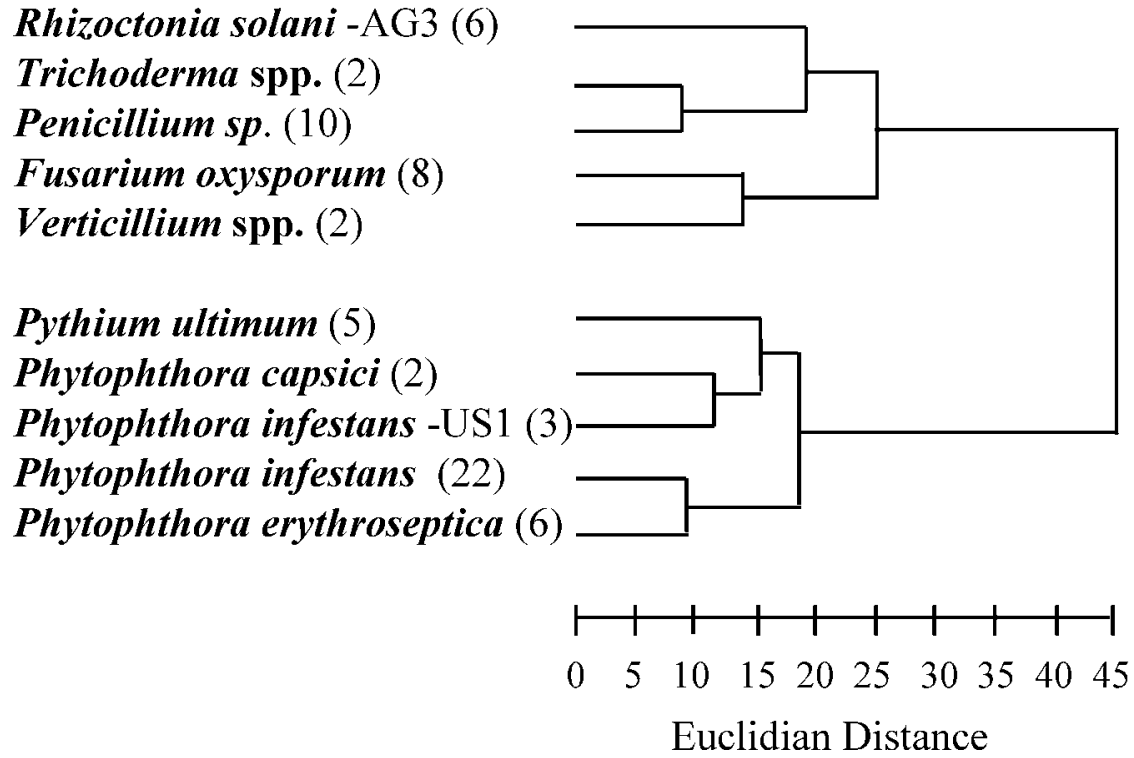

Fig. 2. Dendrogram of isolates of Phytophthora infestans in relation to selected other closely and distantly related taxa based on the analysis of fatty acid methyl ester profiles. Values in parentheses represent the number of isolates analyzed for each taxa. Subgroup designations: AG3 refers to anastomosis group 3 of Rhizoctonia solani and US1 refers to the genotype subgroup US-1 based on glucose-6-phosphate isomerase (Gpi) allozyme assay as described in Table 1. 
creased amounts of $16: 1 \omega 7 \mathrm{c}$ and 20:5 $\omega 3 \mathrm{c}$. The effect of temperature on production of 20:4 $\omega 6 \mathrm{c}$ varied among isolates, with greater amounts produced by isolates 99-1 and 99-97 and lesser amounts produced by $99-4$ and $99-3$ at $25^{\circ} \mathrm{C}$ compared with $21^{\circ} \mathrm{C}$. Despite these temperature effects, most of the isolates still exhibited FAME profiles characteristic of their genotypes. Isolates grown at $21^{\circ} \mathrm{C}$ were still identified correctly by the isolate library entries (which were generated from isolates grown at $25^{\circ} \mathrm{C}$ ), although at lower similarity values $(0.50$ to 0.70 compared with 0.75 to 0.86 for the $25^{\circ} \mathrm{C}$ incubation).

The growth media used (PB, PA, and RA) had significant effects on FAME profiles and differential effects among isolates
(Table 5). In particular, the use of the solid PA versus liquid PB media dramatically affected fatty acid composition. Although significant differences in fatty acid contents among media were apparent for all the major fatty acids produced, the effects of medium varied among the isolates tested. For example, growth on PA resulted in production of the highest amount of 14:0 among the media for isolate 99-3, but the lowest amount of 14:0 for isolate 99-1. Overall, growth on PA tended to result in higher amounts of 18:2 $\omega 6 \mathrm{c}$ and lower amounts of 18:1 $\omega 9 \mathrm{c}$, and growth on RA resulted in higher amounts of 16:0 and lower amounts of 20:5 $\omega 3 \mathrm{c}$ compared with the other media. Growth in PB produced variable results among the isolates. Fatty

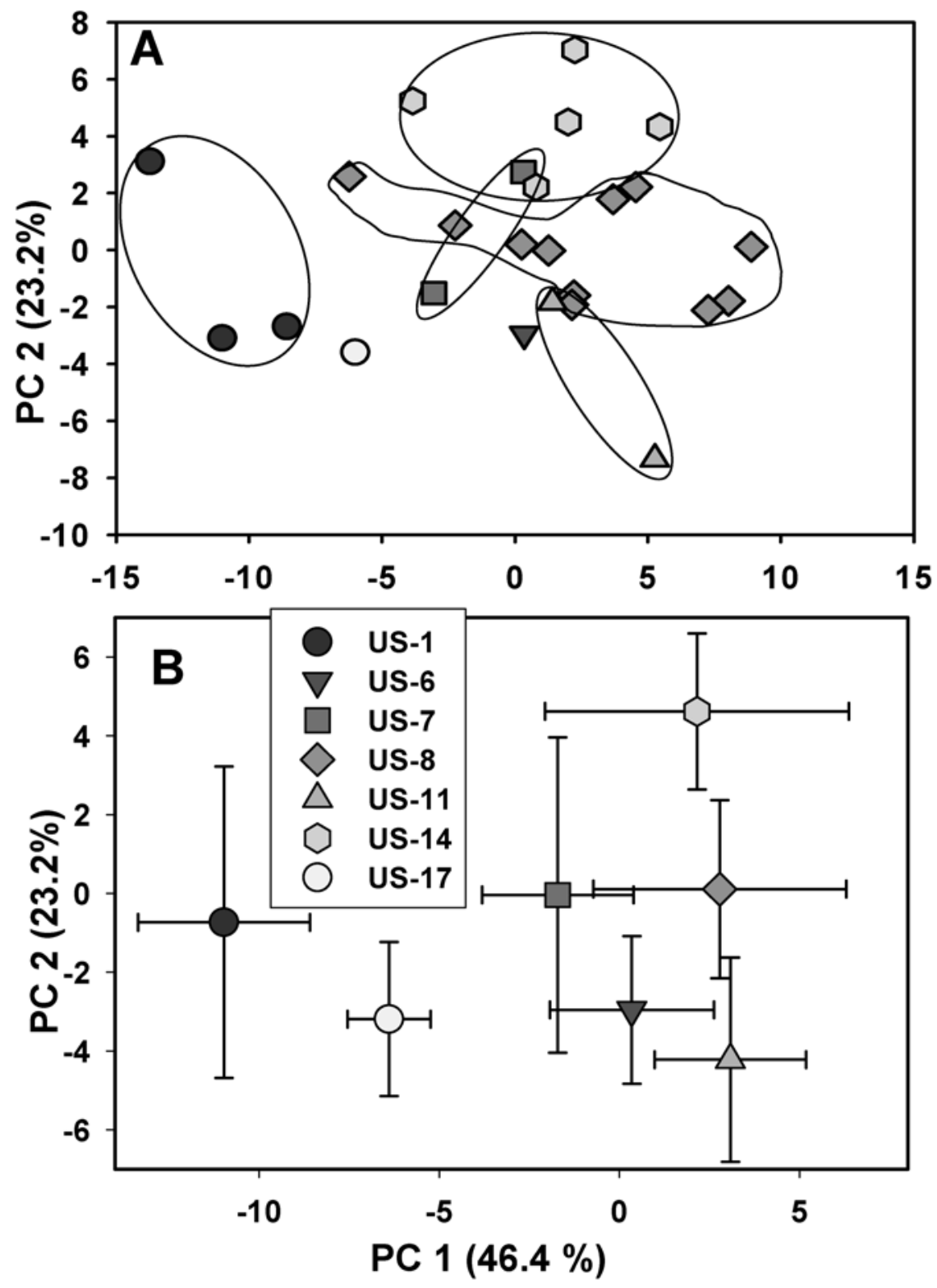

Fig. 3. Relationship of fatty acid profiles of subspecific genotype groups of isolates of Phytophthora infestans as represented by an ordination plot of PC 1 and PC 2 from principal components (PC) analysis as $\mathbf{A}$, a scatter plot of all isolates and $\mathbf{B}$, the average of each genotype grouping. Error bars represent standard errors of the mean. Values in parentheses represent percentage of total variability accounted for by each PC. US-genotype designations are based on the glucose-6-phosphate isomerase assay $(7,8)$ as described in Table 1.

acid contents for all isolates were more variable and less consistent among replicate samples when grown in the liquid PB than on the solid PA plates, as indicated by higher average coefficients of variation (CV) over the five major component fatty acids (Table 5). Culture on PA plates provided noticeably more consistent FAME profiles and significantly lower CV values than PB for all isolates. Based on these results, PA was used as the medium for growth, library establishment, and characterization of $P$. infestans in all assays.

Maintenance of isolates by repeated transfer and prolonged storage in agar cultures also had significant effects on fatty acid profiles over time; however, only some isolates were affected. Over the course of 1 year, profiles of isolates 99-1 and 99-97 were substantially changed, as indicated by changes in PC 1 , which accounted for $56 \%$ of the total variability among all isolates and storage times tested (Fig. 6). Regression analysis indicated a significant linear increase $(P=0.002$, slope $\left.=1.43, R^{2}=0.48\right)$ in PC 1 for isolate 99-1 (US-1) and a significant linear decrease $(P$ $<0.001$, slope $=-2.41, R^{2}=0.71$ ) for isolate 99-97 (US-14). PC 1 was determined primarily by the fatty acids $14: 0,16: 0,18: 2$ $\omega 6 \mathrm{c}$, and 20:5 $\omega 3 \mathrm{c}$. There was no change in PC 1 or other aspects of the fatty acid profiles for isolates $99-2$, 99-3, or 99-4 (Fig. 6).

Library evaluation and utilization. When the FAME profile libraries established from the 25 core isolates of $P$. infestans were used to identify five unknown isolates that had been previously profiled and included in the libraries, all five of the isolates were correctly identified to genotype and positively identified as the correct isolate (Table 6). Although the similarity values for multiple samples of each isolate varied, ranging from 0.41 to 0.89 , strong positive identifications were made for four of the five isolates (average similarity of 0.67 to 0.70 ). There was difficulty in identifying only one of the isolates, 99-64, which was more variable among samples and had lower overall similarity values, but FAME profile analyses still resulted in a correct tentative identification (Table 6). For all five test isolates, there were no other isolate library profiles that also had a high similarity value, which made the distinction among library entries clear.

Characterization of 10 additional isolates collected from Maine in 2000, including some isolates with "standard" genotypes (US-8 and US-14) and some with variant genotypes (Gpi 100/100, 100/111, and 122/122), indicated that FAME profiles of several of the new isolates corresponded well with the genotype characteristics represented in the libraries (Table 7). However, one US-8 isolate (00-38) and one US-14 isolate (00-39) did not have a high similarity to any of the library entries. Isolates with variant genotypes included 
three that were Gpi 100/100 and had RG57 fingerprints different from US-6 (which also is Gpi 100/100) and similar to that produced by US-17 (Table 1). Also included were isolates of Gpi 100/111, $100 / 122$, and $100 / 122$, all of which had the same RG57 fingerprint as US-8 (Table 1). FAME profiles of some of these isolates with variant genotypes did not correspond well with the library profiles, but those of others did. Isolates 00-1 (US-8) and 00-6 (Gpi 122/122) had a high similarity to the US- 8 profile in the genotype library, indicating that these isolates have profiles very similar to other US-8 isolates in the library (Table 7). Isolates 00-58 (US-14) and 00-3 (Gpi 100/111) had comparably high similarities to both the US-8 and US-14 profiles, demonstrating the similarity among isolates within these libraries and potential difficulty in distinguishing their profile characteristics. Isolate 00-73 (Gpi 122/122) did not correspond well with any of the library profiles. Thus, the two isolates examined with Gpi 122/122 had very different profiles, one similar to US- 8 isolates and one somewhat different from all library entries. The three isolates examined with Gpi 100/100 all had FAME profiles very similar to each other and moderately similar (0.4 to 0.5$)$ to several different genotype library entries (US-8, US-7, US1 , and US-11), but not highly similar to any one. Thus, a new genotype group was established in the library to represent these isolates. All three isolates had a similarity of $>0.7$ to this new group. Interestingly, profiles from this group were not similar to the US-6 or US-17 library entry, although the genetic characteristics appear closer to these groups than any other.

\section{DISCUSSION}

Fatty acid profiles derived from isolates of $P$. infestans with diverse genetic characteristics were distinct from those of other closely related organisms, such as $P$. capsici, P. erythroseptica, and Pythium ultimum, as well as very different from more distantly related taxa, such as filamentous fungi. Although only two other species of Phytophthora were included in this study, the differences among the three species were clear and prominent, suggesting that there are distinct fatty acid characteristics associated with particular species within Phytophthora. Another recent report (4) also observed distinctive FAME profiles that differentiated five other Phytophthora species ( $P$. cactorum, $P$. citrophthora, $P$. cinnamomi, $P$. cryptogea, and $P$. nicotianae). Results from that study (4) indicated the same predominant fatty acids were produced by species of Phytophthora as in the present study. Beyond this, our results indicate that FAME profiles may also be used to differentiate subgroups within species. This is consistent with results from other fungi, where FAME profiles can be valuable for characterizing and differentiat- ing not only among closely related species, but also among subgroups within species $(14,16,21,25)$. In a series of papers focused on Rhizoctonia solani, Stevens Johnk and Jones (22-25) used FAME profiles to successfully differentiate among different anastomosis groups, as well as among subgroups within anastomosis groups AG1, AG2-2, AG-3, and AG-4. With bacteria,
FAME profiles are sufficiently specific that individual strains can be determined (19).

Profile characteristics within $P$. infestans were quite diverse and corresponded to some degree with genetic (genotype) characteristics. Isolates of the US-1 genotype, in particular, had different profile characteristics than all other isolates of $P$. infestans. US-1 represents the "old" clonal



Fig. 4. Relationship of fatty acid profiles of subspecific genotype groups of isolates of Phytophthora infestans as represented by a three-dimensional plot of PC 1 to 3 from principal components (PC) analysis and grouped by genotype designation. Values in parentheses represent the percentage of total variability accounted for by each PC. US-genotype designations are based on the glucose-6phosphate isomerase assay $(7,8)$ as described in Table 1 .

\section{Phytophthora capsici (2) \\ Phytophthora infestans - US-1 (3) \\ Phytophthora infestans - US-17 (1) \\ Phytophthora infestans - US-6 (1) \\ Phytophthora infestans - US-7 (2) \\ Phytophthora infestans - US-8 (11) \\ Phytophthora infestans - US-14 (5) \\ Phytophthora infestans - US-11 (2) \\ Phytophthora erythroseptica (6)}

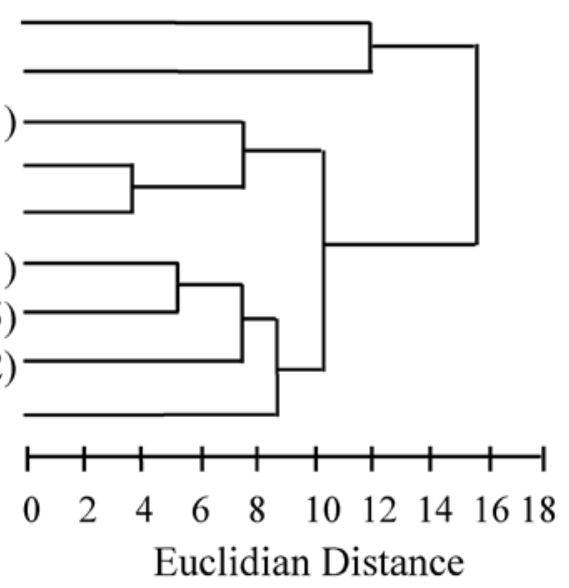

Fig. 5. Dendrogram of subspecific genotype groups of isolates of Phytophthora infestans in relation to $P$. capsici and $P$. erythroseptica based on the analysis of fatty acid methyl ester profiles. USgenotype designations are based on the glucose-6-phosphate isomerase assay $(7,8)$ as described in Table 1 . 
lineage genotype that was predominant in the United States and most of the world from the time of the devastating late blight epidemics of the 1840 s until its recent displacement by "new" genotypes (such as US-7, US-8, and US-14) and variants, which generally are mating type A2 and are more aggressive and epidemiologically fit (8). The US-1 group is genetically very different from the other genotypes, and it is not surprising that FAME characteristics of this group are the most distinct from other isolates of $P$. infestans.

Profiles of individual isolates of $P$. infestans were consistent and reproducible over time. As long as culture conditions, such as growth medium, incubation temperature, and incubation time, were kept constant, fatty acid characteristics were relatively stable with only minor variation in repeated testing for over a year in this study. This is consistent with other reports on fatty acid profiles conducted using other fungi $(21,26)$. However, there was considerable variability among individual sample extractions. Thus, although the average profiles derived from extractions of multiple samples of the same isolate were consistent and maintained specific isolate and/or group characteristics, individual samples could vary substantially. For example, a single sample from an isolate occasionally did not closely match the library characteristics of that isolate, and if characterization was based on this single sample, the isolate would not be correctly identified. So, for accurate and reliable results, at least six, and preferably eight to 10 samples are necessary to produce identifiable profile characteristics.

As expected, culture conditions such as growth medium and incubation temperature significantly affected FAME profiles of isolates of $P$. infestans in this study, as has been observed previously with other fungi $(21,26)$. For each of these factors, there were differences in FAME profiles among the isolates in response to the altered growth conditions. Changes in growth medium, in particular, resulted in major differences in fatty acid composition among the isolates representing different genotype groups. Cultures grown in pea broth had different FAME profiles and were more variable than those grown on pea agar plates. This may be due to an additional cultural factor that significantly affects fatty acid production, physiological age $(18,20)$. Although liquid cultures apparently work fine for fungi that grow fairly rapidly (e.g., Rhizoctonia, Fusarium, Penicillium, etc.) $(21,26)$, the slow growth of $P$. infestans produces cultures with mycelia of vastly different ages. This may be the cause of the variable profiles that were observed in liquid versus solid culture in this study. In solid culture, due to radial growth from the center, the younger, more actively growing mycelia can be separated

Table 4. Effect of incubation temperature on relative fatty acid contents (\% of total) of eight predominant fatty acids recovered from five isolates of Phytophthora infestans that represent different genotype groups

\begin{tabular}{|c|c|c|c|c|c|c|c|c|c|c|}
\hline \multirow{2}{*}{$\begin{array}{l}\text { Isolate } \\
\left(\text { geno. }^{y}\right)\end{array}$} & \multirow{2}{*}{$\underset{{ }^{\circ} \mathbf{C}}{\text { Temp. }}$} & \multicolumn{8}{|c|}{ Fatty acid } & \multirow[b]{2}{*}{ Total } \\
\hline & & $14: 0$ & $16: 1 \omega 7 \mathrm{c}$ & $16: 0$ & $18: 3 \omega 6 c$ & $18: 2 \omega 6 c$ & $18: 1 \omega 9 \mathrm{c}$ & $20: 4 \omega 6 c$ & $20: 5 \omega 3 c$ & \\
\hline \multirow[t]{2}{*}{ 99-1 (US-1) } & 21 & 14.7 & 1.5 & 20.9 & 2.3 & 23.4 & 11.0 & 1.7 & $22.7 * z$ & 98.2 \\
\hline & 25 & 16.0 & 1.3 & 19.6 & 2.6 & 24.3 & 11.3 & $2.3^{*}$ & 18.9 & 96.3 \\
\hline \multirow[t]{2}{*}{ 99-4 (US-11) } & 21 & 27.1 & $5.0^{*}$ & 16.8 & 1.1 & 24.7 & 5.9 & $1.6^{*}$ & $14.5^{*}$ & 96.7 \\
\hline & 25 & 26.6 & 3.6 & 17.4 & 0.5 & $30.6 *$ & $7.7 *$ & 1.1 & 10.6 & 98.1 \\
\hline \multirow[t]{2}{*}{ 99-2 (US-7) } & 21 & 24.2 & $4.7 *$ & 18.9 & 1.5 & 22.8 & 5.2 & 1.8 & 18.6 & 97.7 \\
\hline & 25 & 22.7 & 2.8 & 19.5 & 0.9 & $25.9 *$ & $6.3^{*}$ & 2.0 & 18.5 & 98.6 \\
\hline \multirow[t]{2}{*}{ 99-3 (US-8) } & 21 & 24.8 & $3.8^{*}$ & 14.7 & 1.6 & 22.8 & 5.6 & $2.4^{*}$ & $22.7 *$ & 98.4 \\
\hline & 25 & 25.9 & 3.2 & $16.6^{*}$ & 1.8 & $24.6^{*}$ & $8.9 *$ & 1.5 & 16.8 & 99.3 \\
\hline \multirow[t]{2}{*}{ 99-97(US-14) } & 21 & 26.8 & 2.4 & 14.4 & $2.5^{*}$ & 20.2 & 10.8 & 2.2 & $19.1^{*}$ & 98.4 \\
\hline & 25 & 27.2 & 2.2 & $16.5^{*}$ & 1.8 & 19.3 & $12.3 *$ & $2.7^{*}$ & 15.9 & 97.9 \\
\hline
\end{tabular}

${ }^{\text {y }}$ US genotype designations represent known differences in genetic characteristics based on glucose-6-phosphate isomerase (Gpi) allozyme assay $(7,8)$ as described in Table 1.

${ }^{\mathrm{z}}$ Means followed by an asterisk are significantly greater than the corresponding mean for that isolate according to analysis of variance at $P=0.05$. Means are based on combined results of two trials, each consisting of at least five samples per isolate and incubation temperature, and grown on pea broth agar for 14 days prior to extraction and analysis of fatty acids.

Table 5. Effect of growth medium on relative fatty acid contents (\% of total) and the average associated coefficient of variation (CV) for the five most abundant fatty acids in four isolates of Phytophthora infestans that represent different genotype groups

\begin{tabular}{|c|c|c|c|c|c|c|c|c|c|}
\hline \multirow{2}{*}{$\begin{array}{l}\text { Isolate } \\
\text { (geno.v) }\end{array}$} & \multirow[b]{2}{*}{ MT $^{w}$} & \multirow[b]{2}{*}{ Medium $^{x}$} & \multicolumn{5}{|c|}{ Fatty acid } & \multirow[b]{2}{*}{ Total } & \multirow[b]{2}{*}{$\mathrm{CV}^{\mathbf{y}}$} \\
\hline & & & $14: 0$ & 16:0 & $18: 2 \omega 6 c$ & 18:1 $\omega 9 \mathrm{c}$ & $20: 5 \omega 3 c$ & & \\
\hline \multirow[t]{3}{*}{ 99-1 (US-1) } & A1 & $\mathrm{PB}$ & $18.1 \mathrm{a}^{\mathrm{z}}$ & $19.4 \mathrm{c}$ & $20.2 \mathrm{c}$ & $19.6 \mathrm{a}$ & $12.4 \mathrm{~b}$ & 89.7 & $19.9 \mathrm{a}$ \\
\hline & & RA & $17.4 \mathrm{a}$ & $25.4 \mathrm{a}$ & $24.2 \mathrm{~b}$ & $17.7 \mathrm{a}$ & $7.8 \mathrm{c}$ & 92.5 & $10.8 \mathrm{~b}$ \\
\hline & & PA & $12.3 \mathrm{~b}$ & $23.3 \mathrm{~b}$ & $29.8 \mathrm{a}$ & $7.9 \mathrm{~b}$ & $20.2 \mathrm{a}$ & 93.5 & $11.8 \mathrm{~b}$ \\
\hline \multirow[t]{3}{*}{ 99-4 (US-11) } & A1 & $\mathrm{PB}$ & $27.0 \mathrm{a}$ & $17.9 \mathrm{~b}$ & $25.3 \mathrm{a}$ & $11.7 \mathrm{~b}$ & $7.9 \mathrm{~b}$ & 89.8 & $17.3 \mathrm{a}$ \\
\hline & & RA & $24.1 \mathrm{~b}$ & $26.0 \mathrm{a}$ & $19.9 \mathrm{~b}$ & $14.6 \mathrm{a}$ & $5.4 \mathrm{c}$ & 90.0 & $13.4 \mathrm{ab}$ \\
\hline & & PA & $25.4 \mathrm{ab}$ & $19.7 \mathrm{~b}$ & $27.3 \mathrm{a}$ & $8.0 \mathrm{c}$ & $9.7 \mathrm{a}$ & 90.1 & $10.3 \mathrm{~b}$ \\
\hline \multirow[t]{3}{*}{ 99-3 (US-8) } & $\mathrm{A} 2$ & $\mathrm{~PB}$ & $24.0 \mathrm{~b}$ & $17.6 \mathrm{~b}$ & $15.3 \mathrm{~b}$ & $21.9 \mathrm{a}$ & $11.1 \mathrm{~b}$ & 89.9 & $24.1 \mathrm{a}$ \\
\hline & & RA & $21.8 \mathrm{c}$ & $21.5 \mathrm{a}$ & $21.9 \mathrm{a}$ & $14.4 \mathrm{~b}$ & $11.3 \mathrm{~b}$ & 90.9 & $14.5 \mathrm{~b}$ \\
\hline & & PA & $27.5 \mathrm{a}$ & $15.7 \mathrm{c}$ & $24.5 \mathrm{a}$ & $7.9 \mathrm{c}$ & $17.0 \mathrm{a}$ & 92.6 & $12.9 \mathrm{~b}$ \\
\hline \multirow[t]{3}{*}{ 99-97(US-14) } & $\mathrm{A} 2$ & $\mathrm{~PB}$ & $27.2 \mathrm{~b}$ & $12.9 \mathrm{~b}$ & $12.1 \mathrm{~b}$ & $27.2 \mathrm{a}$ & $10.7 \mathrm{~b}$ & 90.1 & $28.7 \mathrm{a}$ \\
\hline & & RA & $31.6 \mathrm{a}$ & $18.8 \mathrm{a}$ & $18.3 \mathrm{a}$ & $16.7 \mathrm{~b}$ & $6.8 \mathrm{c}$ & 92.2 & $17.9 \mathrm{ab}$ \\
\hline & & PA & $31.6 \mathrm{a}$ & $13.5 \mathrm{~b}$ & $21.1 \mathrm{a}$ & $8.0 \mathrm{c}$ & $17.3 \mathrm{a}$ & 91.5 & $13.1 \mathrm{~b}$ \\
\hline
\end{tabular}

${ }^{\mathrm{v}}$ US genotype designations represent known differences in genetic characteristics based on glucose-6-phosphate isomerase (Gpi) allozyme assay $(7,8)$ as described in Table 1.

${ }^{\text {w}}$ Mating type.

${ }^{\mathrm{x}}$ Growth medium; $\mathrm{PB}=$ pea broth (liquid culture), $\mathrm{RA}=$ Rye A agar (solid), $\mathrm{PA}=$ pea broth agar (solid). All cultures were grown for 14 days at $25^{\circ} \mathrm{C}$

${ }^{y}$ Mean coefficient of variation associated with fatty acid contents averaged over all five fatty acids and calculated as the standard deviation divided by the mean.

${ }^{\mathrm{z}}$ Means followed by the same letter within columns for each isolate are not significantly different according to Fisher's protected least significant difference (LSD) at $P=0.05$. Means are based on combined results of two tests, each consisting of at least six samples per isolate/medium combination. 
from the older center portion. In this study, the center $3-\mathrm{cm}$ portion of the plate was not harvested, resulting in better control of the physiological age of the mycelia and more consistent results.

Temperature effects, although significant, were relatively minor in comparison to other factors. In general, our results were consistent with other reports which indicated that as the incubation temperature decreased, the degree of unsaturation in fatty acids increased (21) and that changes in temperature affect isolates and species differently $(21,26)$. However, since the difference between the temperatures used in this study was only $4^{\circ} \mathrm{C}$, large differences were not expected nor observed.
Stahl and Klug (21) observed that differences of $3^{\circ} \mathrm{C}$ or less did not substantially affect FAME profiles of several different fungi and did not interfere with producing consistent FAME profiles.

Overall, fatty acid data corresponded well with known genetic characteristics, such as Gpi analysis and RG57 fingerprint patterns, of the P. infestans isolates. Although fatty acid characteristics of isolates within a particular genotype varied somewhat, there was a definite association between isolate profiles and genotype characteristics. However, it must be noted that in the rudimentary genotype library assembled here, most genotype groups contained very few isolates, and obviously not

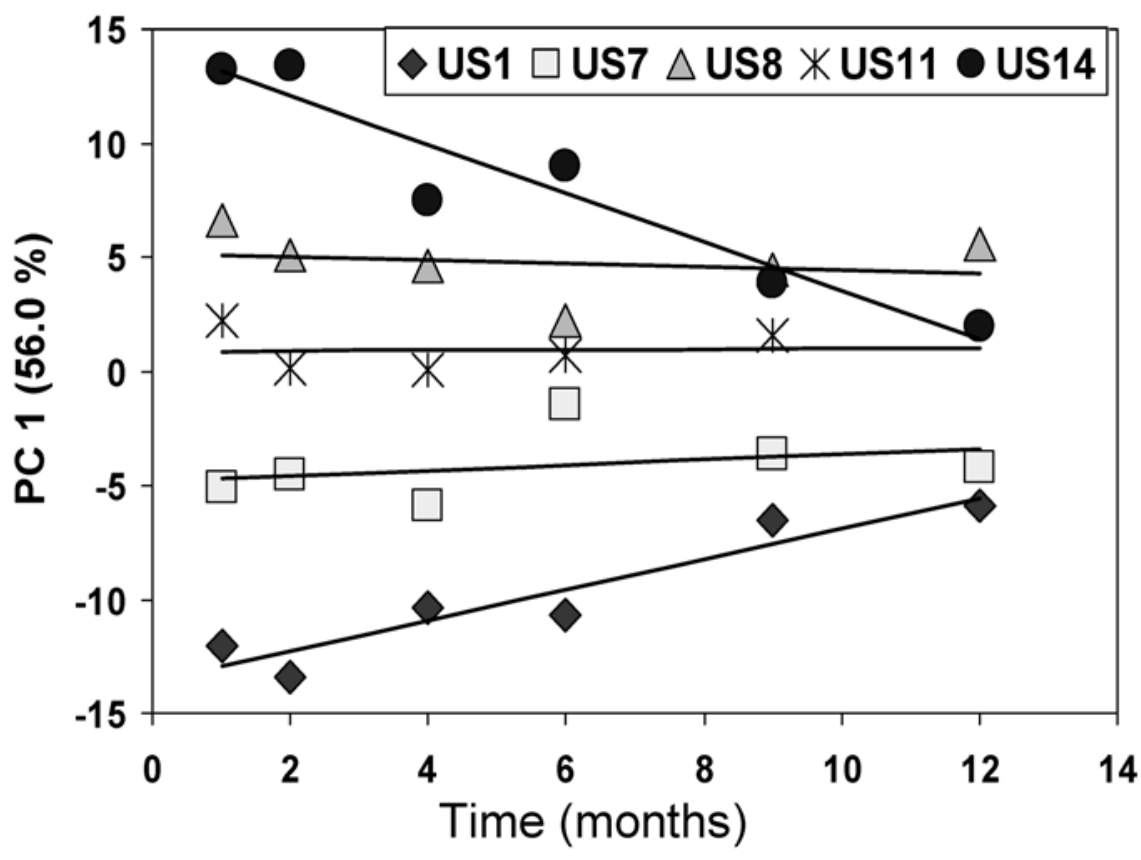

Fig. 6. Effects of repeated transfer and prolonged culture on agar medium on fatty acid profiles of five isolates of Phytophthora infestans that represent different genotype groups (US-1, -7, -8, -11, and -14) as represented by PC 1 of principle component (PC) analysis. Value in parentheses represents the percentage of total variability accounted for by PC 1 . Stock cultures were grown on Rye A agar at $21^{\circ} \mathrm{C}$ and transferred to new plates approximately every 2 months for 1 year. Fresh pea broth agar plates were made from these cultures at $1,2,4,6,9$, and 12 months, incubated at $25^{\circ} \mathrm{C}$ for 14 days, and analyzed for fatty acids. At least six replicate samples of each isolate/time combination were used. enough to make any definitive determinations. For less common genotypes, such as US- $6,-7,-11$, and -17 , only one or two isolates were in the library. This was because the objective of this study was to look at a wide variety of different isolates to determine the utility of fatty acid profiles in characterizing isolates of $P$. infestans, rather than establishing a comprehensive library for characterization. In the genotype groups where more isolates were characterized (US-8 and US-14), it did appear that the more isolates that were included, the more variable the group became, with much variability among isolates. Even with the US-7 and US-11 groups, which contained only two isolates each, there were notable profile differences between individual isolates. Nonetheless, some genotype group characteristics were detectable through multivariate analysis techniques.

Because each isolate profile was consistent and often distinct from other isolates in each genotype group, it is possible that fatty acid data may be useful beyond the characterization of broad genetic groups; FAME profile analysis may be capable of detecting even smaller differences in genetic characteristics or epidemiological traits. With careful scrutiny, FAME profiles may be useful for identifying individual isolates or strains, as has been done with bacteria (19). In our blind isolate test, five isolates previously profiled were correctly identified not only to genotype, but to the specific isolate, several months after the original libraries were established. However, it has yet to be determined whether an isolate put in the field or into a plant and then recovered would still have the same characteristic FAME profile. This potential use of fatty acid data has intriguing possibilities for monitoring, tracking, and identification of individual isolates. One clear result of these tests was that the profiles were more isolate-specific than genotype designation-specific, with a variety of different isolate profiles within each genotype.

Our attempt to characterize new isolates collected in Maine in 2000 emphasized

Table 6. Identification of five previously characterized isolates of Phytophthora infestans as unknowns in a blind test using established fatty acid profile database libraries

\begin{tabular}{|c|c|c|c|c|c|c|c|c|}
\hline \multicolumn{2}{|c|}{ Isolate $^{\mathrm{x}}$} & \multicolumn{3}{|c|}{ Genotype library } & \multicolumn{3}{|c|}{ Isolate library ${ }^{y}$} & \multirow[b]{2}{*}{ Result $^{z}$} \\
\hline Letter & Actual ID & Genotype & Similarity & Range & Isolate & Similarity & Range & \\
\hline A & $99-64$ & US-14 & 0.468 & $0.35-0.52$ & $99-64$ & 0.537 & $0.41-0.71$ & Tentative ID \\
\hline B & $99-22$ & US-11 & 0.723 & $0.66-0.82$ & $99-22$ & 0.673 & $0.54-0.80$ & Positive ID \\
\hline $\mathrm{C}$ & $99-1$ & US-1 & 0.662 & $0.59-0.74$ & $99-1$ & 0.692 & $0.63-0.80$ & Positive ID \\
\hline D & $99-25$ & US-6 & 0.695 & $0.45-0.85$ & $99-25$ & 0.695 & $0.45-0.85$ & Positive ID \\
\hline E & $99-3$ & US-8 & 0.630 & $0.46-0.84$ & $99-3$ & 0.701 & $0.48-0.89$ & Positive ID \\
\hline
\end{tabular}

${ }^{\mathrm{x}}$ Isolates were arbitrarily chosen and given a letter designation by an independent third party. Actual isolate identification (isolate number) of each unknown was concealed. Isolates were grown on pea broth agar at $25^{\circ} \mathrm{C}$ for 14 days, analyzed for fatty acid content, and compared with library profiles. At least six samples of each isolate were analyzed.

${ }^{y}$ Genotype library and isolate library columns list the results of FAME profile comparisons with the database library containing profile data grouped by US-genotype and individual isolates, respectively. Genotype $=$ genotype library entry most closely matching unknown isolate profile. Isolate $=$ isolate library entry most closely matching unknown isolate profile. Similarity $=$ average similarity index for all isolate samples. Range $=$ range of values for similarity index of multiple samples. Similarity index indicates how closely an isolate profile matches the library entry.

${ }^{\mathrm{z}}$ Interpretation of results. A similarity index of 0.6 or higher indicates a positive identification and 0.5 to 0.6 a tentative identification. 
both the strengths and weaknesses of our rudimentary libraries. Several of the isolates corresponded well with the US- 8 and US-14 library entries, but other isolates had a genotype different from anything in the library (Gpi 100/100 variant isolates from tomato) and, therefore, were identified as different genotypes. However, some isolates that corresponded to US-8 and US14 by $G p i$ analysis were not highly similar to anything in our library, indicating that the libraries are still incomplete and do not contain the entire range of profiles found within these genotypes. The other isolates with variant genotypes (Gpi 100/111 and 122/122) found in Maine in 2000 are presumed to be derived from US-8 isolates which have lost Gpi alleles, as in US-14 (11). In our characterization of these variant isolates, the FAME profile from the Gpi 100/111 isolate had high similarity to that of both US-8 and US-14 isolates, supporting the relationship to these groups. Likewise, one of the Gpi 122/122 isolates (00-6) also had a high similarity to the US8 library. However, the other Gpi 122/122 tested (00-73) had a low similarity to all other isolates in the libraries, indicating that two isolates within the same genotype can be very different from each other. Additional information on the genetic characterization of these variant genotypes and their potential significance, as well as more complete information on the populations of $P$. infestans recovered in Maine in 1999 and 2000, was published (11).

In summary, FAME profile analysis does have applicability for use in characterizing and differentiating isolates of $P$. infestans. Although more work needs to be done to make this a useful tool, it is clear that there is potential for expanding the available information that can be derived from isolates of $P$. infestans, as well as other oomycetous pathogens. Potential exists for discerning smaller differences in isolate traits than is currently available through routine characterization tests. There are, however, several potential disadvantages to FAME profile analysis that may interfere with routine use for characterization of these organisms. First and foremost is the need for rigorous control and standardization of culture conditions and extraction protocols. In practice, culture conditions and extraction techniques will vary somewhat from lab to lab. This may make it difficult to develop and share database libraries, and databases may need to be re-established or refined at each location. Another problem is that individual samples are not definitive and several sample runs are required to produce reliable results. Compared to molecular approaches, where definitive results are expected from each sample, this may seem cumbersome. On the other hand, once the appropriate equipment is obtained, fatty acid profile analysis is relatively simple, quick, and economical. Many diagnostic labs already have and use the technology for identification of bacteria. Considering that it may provide a way to examine isolate traits or characteristics that are not readily detected by other means, FAME profiling could prove very useful. It should be emphasized, however, that FAME profiling is intended as a supplemental and complementary tool for characterization of isolates and should not be considered an alternative or replacement for more established means of cultural and genetic char- acterization. The greatest utility of these FAME profiles may be in their potentially greater isolate-specificity than other tests, possibly resulting in establishing relationships between profile characteristics and specific isolate traits, such as pathogen aggressiveness, sporulation, or other characteristics that may be useful in determining epidemiological consequences.

\section{ACKNOWLEDGMENTS}

Special thanks to M. T. Brewer and E. R. Champaco for valuable technical assistance, and C. Corio and J. Magoon for additional assistance. We thank D. Lambert and S. Johnson for assistance in obtaining late blight samples, and $\mathrm{M}$. Cubeta and W. E. Fry for providing isolates.

\section{LITERATURE CITED}

1. Augustyn, O. P. H., Kock, J. F. L., and Ferriera, D. 1990. Differentiation between yeast species and strains within a species by cellular fatty acid analysis. Syst. Appl. Microbiol. 13:44-45.

2. Brondz, I., Olsen, I., and Sjostrom, M. 1989. Gas chromatographic assessment of alcoholized fatty acids from yeasts: A new chemotaxonomic method. J. Clin. Microbiol. 27:2815-2819.

3. Caten, C. E., and Jinks, J. L. 1968. Spontaneous variability of single isolates of Phy tophthora infestans. I. Cultural variation. Can. J. Bot. 46:329-348.

4. Duan, C.-H., Riley, M. B., and Jeffers, S. N. 2002. Fatty acid production by species of Phytophthora: Potential for identification. (Abstr.) Phytopathology 92:S21.

5. Fraser, D. E., Shoemaker, P. B., and Ristaino, J. B. 1999. Characterization of isolates of Phytophthora infestans from tomato and potato in North Carolina from 1993 to 1995 Plant Dis. 83:633-638.

6. Goodwin, S. B., Drenth, A., and Fry, W. E 1992. Cloning and genetic analysis of two highly polymorphic moderately repetitive nuclear DNAs from Phytophthora infestans. Curr. Genet. 22:107-115.

Table 7. Characterization of additional isolates of Phytophthora infestans collected in 2000 using established fatty acid profile database libraries

\begin{tabular}{|c|c|c|c|c|c|}
\hline \multirow[b]{2}{*}{ Isolate no. } & \multirow[b]{2}{*}{ Genotype $^{x}$} & \multicolumn{3}{|c|}{ Genotype library $^{\mathrm{y}}$} & \multirow[b]{2}{*}{ Interpretation of results ${ }^{\mathrm{z}}$} \\
\hline & & Genotype & Similarity & Range & \\
\hline \multirow[t]{2}{*}{$00-1$} & US-8 & US-8 & 0.662 & $0.43-0.86$ & \multirow[t]{2}{*}{ Profile highly similar to other US-8 isolates in database library } \\
\hline & & US-14 & 0.597 & $0.43-0.89$ & \\
\hline $00-38$ & US-8 & US-8 & 0.369 & $0.17-0.45$ & Low similarity to other US- 8 isolates in library \\
\hline \multirow[t]{2}{*}{$00-39$} & US-14 & US-14 & 0.305 & $0.15-0.55$ & \multirow[t]{2}{*}{ Low similarity to other US- 8 \& US-14 isolates in library } \\
\hline & & US-8 & 0.285 & $0.22-0.37$ & \\
\hline \multirow[t]{2}{*}{$00-58$} & US-14 & US-8 & 0.588 & $0.44-0.73$ & \multirow{4}{*}{$\begin{array}{l}\text { Profile with comparably high similarity to both US-8 \& US-14 } \\
\text { isolates in library } \\
\text { Profile with very high similarity to both US-8 \& US-14 genotype } \\
\text { isolates in library }\end{array}$} \\
\hline & & US-14 & 0.569 & $0.42-0.70$ & \\
\hline \multirow[t]{2}{*}{$00-3$} & $100 / 111$ & US-8 & 0.717 & $0.55-0.92$ & \\
\hline & & US-14 & 0.730 & $0.52-0.84$ & \\
\hline $00-6$ & $122 / 122$ & US-8 & 0.636 & $0.34-0.83$ & \multirow{8}{*}{$\begin{array}{l}\text { Profile similar to US-8 isolates in library } \\
\text { Low similarity to all other isolates in library } \\
\text { Profiles of all three Gpi 100/100 isolates had comparable midrange } \\
\text { similarity to several genotypes (US-8, US-7, US-1, and US-11) } \\
\text { and were very similar to each other. A new genotype group was } \\
\text { established in the database to represent these isolates. }\end{array}$} \\
\hline $00-73$ & $122 / 122$ & US-14 & 0.370 & $0.15-0.56$ & \\
\hline \multirow[t]{2}{*}{$00-15$} & \multirow[t]{2}{*}{$100 / 100$} & US-8 & 0.450 & $0.29-0.68$ & \\
\hline & & US-7 & 0.507 & $0.29-0.66$ & \\
\hline \multirow[t]{2}{*}{$00-22$} & \multirow[t]{2}{*}{$100 / 100$} & US- 8 & 0.417 & $0.29-0.65$ & \\
\hline & & US-1 & 0.496 & $0.32-0.57$ & \\
\hline \multirow[t]{2}{*}{$00-87$} & \multirow[t]{2}{*}{$100 / 100$} & US-8 & 0.497 & $0.29-0.76$ & \\
\hline & & US-7 & 0.508 & $0.35-0.57$ & \\
\hline
\end{tabular}

${ }^{x}$ US genotype designations represent known differences in genetic characteristics based on glucose-6-phosphate isomerase (Gpi) allozyme assay (7,8) as described in Table 1. Other designations represent results of Gpi allozyme assay and are given to identify variant genotypes with no known US designation.

y Genotype library columns list the results of FAME profile comparisons with the database library containing profile data grouped by US-genotype. Genotype $=$ genotype library entry most closely matching unknown isolate profile. Similarity $=$ average similarity index for all isolate samples. Range $=$ range of values for similarity index of multiple samples. Similarity index indicates how closely an isolate profile matches the library entry. Isolates were grown on pea broth agar at $25^{\circ} \mathrm{C}$ for 14 days, analyzed for fatty acid content, and compared with library profiles. At least six samples of each isolate were analyzed.

${ }^{\mathrm{z}}$ A similarity index of 0.6 or higher indicates a positive identification and 0.5 to 0.6 a tentative identification as a member of that group. 
7. Goodwin, S. B., Schneider, R. E., and Fry, W. E. 1995. Use of cellulose-acetate electrophoresis for rapid identification of allozyme genotypes of Phytophthora infestans. Plant Dis. 79:1181-1185.

8. Goodwin, S. B., Smart, C. D., Sandrock, R. W., Deahl, K. L., Punja, Z. K., and Fry, W. E. 1998. Genetic change within populations of Phytophthora infestans in the United States and Canada during 1994 to 1996: Role of migration and recombination. Phytopathology 88:939-949.

9. Graham, J. H., Hodges, N. C., and Morton, J. B. 1995. Fatty acid methyl ester profiles for characterization of Glomalean fungi and their endomycorrhizae. Appl. Environ. Microbiol. 61:58-64.

10. Griffith, G. W., and Shaw, D. S. 1998. Polymorphisms in Phytophthora infestans: Four mitochondrial haplotypes are detected after PCR amplification of DNA from pure cultures or from host lesions. Appl. Environ. Microbiol. 64:4007-4014.

11. Groves, C. L. 2002. Characterization of Phytophthora infestans from Maine during 1999 and 2000. Am. J. Potato Res. 79:325-333.

12. Groves, C. T., and Ristaino, J. B. 2000. Commercial fungicide formulations induce in vitro oospore formation and phenotypic change in mating type in Phytophthora infestans. Phytopathology 90:1201-1208.

13. Larkin, R. P. Characterization of soil microbial communities under different potato cropping systems by microbial population dynamics, substrate utilization, and fatty acid profiles. Soil Biol. Biochem. In press.
14. Lopes da Silva, T., de Sousa, E., Pereira, P. T., Ferrao, A. M., and Roseiro, J. C. 1998. Cellular fatty acid profiles for the differentiation of Penicillium species. FEMS Microbiol. Lett. 164:303-310.

15. Madan, R., Pankhurst, C., Hawke, B., and Smith, S. 2002. Use of fatty acids for identification of AM fungi and estimation of the biomass of AM spores in soil. Soil Biol. Biochem. 34:125-128.

16. Müller, M. M., Kantola, R., and Kitunen, V. 1994. Combining sterol and fatty acid profiles for characterization of fungi. Mycol. Res. 98:593-603.

17. Ruess, L., Haggblom, M. M., Garcia Zapata, E. J., and Dighton, J. 2002. Fatty acids of fungi and nematodes-possible biomarkers in the soil food chain? Soil Biol. Biochem. 34:745-756.

18. Sasser, M. J. 1990. Identification of bacteria by gas chromatography of cellular fatty acids. Technical note 101. Microbial ID, Inc., Newark, DE.

19. Sasser, M. J. 1990. Tracking a strain using the Microbial Identification System. Technical Note 102. Microbial ID, Inc., Newark, DE.

20. Sasser, M. J. 1991. Identification of bacteria through fatty acid analysis. Pages 199-204 in: Methods of Phytobacteriology. F. Klement, K. Rudolf, and D. C. Sands, eds. Akademiai Kiado, Budapest, Hungary.

21. Stahl, P. D., and Klug, M. J. 1996. Characterization and differentiation of filamentous fungi based on fatty acid composition. Appl. Environ. Microbiol. 62:4136-4146.

22. Stevens Johnk, J., and Jones, R. K. 1992.
Determination of whole-cell fatty acids in isolates of Rhizoctonia solani AG-1 IA. Phytopathology 82:68-72.

23. Stevens Johnk, J., and Jones, R. K. 1993 Differentiation of populations of AG-2-2 of Rhizoctonia solani by analysis of cellular fatty acids. Phytopathology 83:278283.

24. Stevens Johnk, J., and Jones, R. K. 1994 Comparison of whole-cell fatty acid compositions in intraspecific groups of Rhizoctonia solani AG-1. Phytopathology 84:271-275.

25. Stevens Johnk, J., and Jones, R. K. 2001 Differentiation of three homogeneous groups of Rhizoctonia solani anastomosis group 4 by analysis of fatty acids. Phytopathology 91:821-830.

26. Suutqari, M. 1995. Effect of growth temperature on lipid fatty acids of four fungi (Asper gillus niger, Neurospora crassa, Penicillium chrysogenum, and Trichoderma reesei). Arch. Microbiol. 164:212-216.

27. Trout, C. L., Ristaino, J. B., Madritch, M. and Wangsomboondee, T. 1997. Rapid detection of Phytophthora infestans in late blightinfected potato and tomato using PCR. Plant Dis. 81:1042-1048.

28. Veys, A., Callewaert, W., Waelkins, E., and Van Den-Abeele, K. 1989. Application of gasliquid chromatography to the routine identification of nonfermenting gram negative bacteria in clinical specimens. J. Clin. Microbiol. 27:1538-1542.

29. Welch, D. F. 1991. Applications of cellular fatty acid analysis. Clin. Microbiol. Rev. 4:422-438. 